\title{
GaN Electronics For High Power, High Temperature Applications
}

\author{
S.J. Pearton, ${ }^{1}$ F. Ren, ${ }^{2}$ A.P. Zhang, ${ }^{2}$ G. Dang, ${ }^{2}$ X.A. Cao, ${ }^{7}$ K.P. Lee, ${ }^{1}$ H. \\ Cho, ${ }^{1}$ B.P. Gila, J.W. Johnson, ${ }^{2}$ C. Monier, ${ }^{1}$ C.R. Abernathy, ${ }^{1}$ J. Han, ${ }^{4}$ \\ A.G. Baca, ${ }^{4}$ J.-I. Chyi, ${ }^{5}$ C.-M. Lee, ${ }^{5}$ T.-E. Nee, ${ }^{5}$ C.-C. Chuo, ${ }^{6}$ and . \\ S.N.G. $\mathrm{Chu}^{7}$ \\ ${ }^{1}$ Department of Materials Science and Engineering, University of \\ Florida, Gainesville, FL 32611, USA \\ ${ }^{2}$ Department of Chemical Engineering, University of Florida, \\ Gainesville, FL 32611 , USA \\ ${ }^{3}$ Department of Materials Engineering, Miryang National University, \\ Kyungnam, Korea \\ ${ }^{4}$ Sandia National Laboratories, Albuquerque, NM 87185, USA \\ ${ }^{5}$ Department of Electrical Engineering, National Central University, \\ Chung-Li, 32054, Taiwan \\ ${ }^{6}$ Department of Physics, National Central University, \\ Chung-Li, 32054, Taiwan \\ ${ }^{7}$ Bell Laboratories, Lucent Technologies, \\ Murray Hill, NJ 07974, USA
}

\begin{abstract}
A brief review is given of recent progress in fabrication of high voltage $\mathrm{GaN}$ and $\mathrm{AlGaN}$ rectifiers. GaN/AlGaN heterojunction bipolar transistors and GaN metal-oxide semiconductor field effect transistors. Improvements in epitaxial layer quality and in fabrication techniques have led to significant advances in device performance.
\end{abstract}

Keywords: GaN, rectifiers, bipolar transistors, MOSFETs.

\section{Introduction}

\subsection{Symposium: C, Session: \#V111, Unique reference number: C-V111-1}

There are also numerous advantages of the AlGaInN system for high power electronics, including wide bandgaps for high voltage and temperature operation, good transport properties, the availability of heterostructures and finally the experience base accumulated during the development of nitride-based light-emitting diodes and lasers. Most of the work on nitride-based electronics has focused on AlGaN/GaN high electron mobility transistors for power microwave applications [1-6], but there are potential advantages to the use of bipolar transistors (either heterojunction bipolar transistors or bipolar junction transistors) in some applications because of their higher current densities, better linearity and more uniform threshold voltages. GaN/AIGaN bipolar transistors are an attractive option for various

\footnotetext{
“Corresponding author: telephone: 352 846-1181; fax: 352 846-1182; e-mail: spear@mse.ufl.edu Department of Materials Science and Engineering, University of Florida, 100 Rhines Hall, PO Box 116400 , Gainesville, FL 32611-64600, USA
} 


\section{DISCLAIMER}

This report was prepared as an account of work sponsored by an agency of the United States Government. Neither the United States Government nor any agency thereof, nor any of their employees, make any warranty, express or implied, or assumes any legal liability or responsibility for the accuracy, completeness, or usefulness of any information, apparatus, product, or process disclosed, or represents that its use would not infringe privately owned rights. Reference herein to any specific commercial product, process, or service by trade name, trademark, manufacturer, or otherwise does not necessarily constitute or imply its endorsement, recommendation, or favoring by the United States Government or any agency thereof. The views and opinions of authors expressed herein do not necessarily state or reflect those of the United States Government or any agency thereof. 


\section{DISCLAIMER}

Portions of this document may be illegible in electronic image products. Images are produced from the best available original document. 
satellite, radar and communications applications in the $1-5 \mathrm{GHz}$ frequency range, at temperatures $>400^{\circ} \mathrm{C}$ and powers $>100$ Watts. Traditional Si-based technologies cannot support such requirements, but the wide bandgap $\mathrm{GaN}$ materials system is capable of reaching this performance level. A summary of progress in $\mathrm{GaN}$ electronics is given in Table I.

Table I. Historical development of GaN-based electronics.

\begin{tabular}{|c|c|c|}
\hline Year & Event & Authors \\
\hline 1969 & GaN by hydride vapor phase epitaxy & Maruska and Tietjen \\
\hline 1971 & $\begin{array}{l}\text { MIS LEDs } \\
\text { GaN by MOCVD }\end{array}$ & $\begin{array}{l}\text { Pankove et al. } \\
\text { Manasevit et al. }\end{array}$ \\
\hline 1974 & GaN by MBE & Akasaki and Hayashi \\
\hline 1983 & AlN intermediate layer by MBE & Yoshida et al. \\
\hline 1986 & Specular films using AlN buffer & Amano et al. \\
\hline 1989 & p-type Mg-doped GaN by LEEBI and GaN p-n junction LED & Amano et al. \\
\hline 1991 & GaN buffer layer by MOCVD & Nakamura \\
\hline 1992 & $\begin{array}{l}\text { Mg activation by thermal annealing } \\
\text { AlGaN/GaN two-dimensional electron gas }\end{array}$ & $\begin{array}{l}\text { Nakamura et al. } \\
\text { Khan et al. }\end{array}$ \\
\hline 1993 & $\begin{array}{l}\text { GaN MESFET } \\
\text { AlGaN/GaN HEMT } \\
\text { Theoretical prediction of piezoelectric effect in } \mathrm{AlGaN} / \mathrm{GaN}\end{array}$ & $\begin{array}{l}\text { Khan et al. } \\
\text { Khan et al. } \\
\text { Bykhovski et al. }\end{array}$ \\
\hline 1994 & $\begin{array}{l}\text { InGaN/AlGaN DH blue LEDs ( } \mathrm{l} \mathrm{cd} \text { ) } \\
\text { Microwave GaN MESFET } \\
\text { Microwave HFET, MISFET } \\
\text { GaN/SiC HBT }\end{array}$ & $\begin{array}{l}\text { Nakamura et al. } \\
\text { Binari et al. } \\
\text { Binari et al.; Khan et al. } \\
\text { Pankove et al. }\end{array}$ \\
\hline 1995 & AlGaN/GaN HEMT by MBE & Ozgur et al. \\
\hline 1996 & $\begin{array}{l}\text { Doped channel AIGaN/GaN HEMT } \\
\text { lon-implanted GaN JFET } \\
340 \mathrm{~V} V_{G D} \text { AlGaN/GaN HEMT } \\
1^{\text {st }} \text { blue laser diode }\end{array}$ & $\begin{array}{l}\text { Khan et al. } \\
\text { Zolper et al. } \\
\text { Wu et al. } \\
\text { Nakamura and Fosal }\end{array}$ \\
\hline 1997 & $\begin{array}{l}\text { Quantification of piezoelectric effect } \\
\text { AlGaN/GaN HEMT on SiC } \\
1.4 \mathrm{~W} @ 4 \mathrm{GHz} \\
0.85 \mathrm{~W} @ 10 \mathrm{GHz} \\
3.1 \mathrm{~W} / \mathrm{mm} \text { at } 18 \mathrm{GHz}\end{array}$ & $\begin{array}{l}\text { Asbeck et al. } \\
\text { Binari et al.; Ping et al. } \\
\text { Gaska et al. } \\
\text { Thibeault et al. } \\
\text { Siram et al. } \\
\text { Wu et al. } \\
\end{array}$ \\
\hline 1998 & $\begin{array}{l}3.3 \mathrm{~W} \\
\text { p/n junction in LEO GaN } \\
\text { HEMT in LEO GaN } \\
6.8 \mathrm{~W} / \mathrm{mm}(4 \mathrm{~W}) @ 10 \mathrm{GHz} \text { HEMT on SiC } \\
10^{-4} \mathrm{Hooge} \text { factor for HEMT on SiC } \\
1^{\mathrm{st}} \mathrm{AlGaN} / \mathrm{GaN} \mathrm{HBT} \\
1^{\text {st }} \mathrm{GaN} \text { MOSFET }\end{array}$ & $\begin{array}{l}\text { Sullivan et al. } \\
\text { Kozodoy et al. } \\
\text { Mishra et al. } \\
\text { Sheppard et al. } \\
\text { Levinshtein et al. } \\
\text { McCarthy et al. } \\
\text { Ren et al. } \\
\text { Ren et al. }\end{array}$ \\
\hline 1999 & $\begin{array}{l}9.1 \text { W/mm @ } 10 \mathrm{GHz} \text { HEMT on SiC } \\
\text { GaN BJT (npn) }\end{array}$ & $\begin{array}{l}\text { Mishra et al. } \\
\text { Yoshida et al. }\end{array}$ \\
\hline 2000 & $\begin{array}{l}4.3 \mathrm{kV} \text { AlGaN rectifier } \\
\text { pnp GaN/AIGaN HBT } \\
\text { pnp GaN BJT }\end{array}$ & $\begin{array}{l}\text { Zhang et al. } \\
\text { Zhang et al. } \\
\text { Zhang et al. }\end{array}$ \\
\hline
\end{tabular}


In addition there is a strong interest in developing high current, high voltage switches in the AlGaN materials system for applications in the transmission and distribution of electric power and in the electrical sub-systems of emerging vehicle, ship and aircraft technology. It is expected that packaged switches made from AlGaN may operate at temperatures in excess of $250^{\circ} \mathrm{C}$ without liquid cooling, thereby reducing system complexity, weight and cost. In terms of voltage requirements, there is a strong need for power quality enhancement in the $13.8 \mathrm{kV}$ class, while it is estimated that availability of $20-25$ $\mathrm{kV}$ switches in a single unit would cause a sharp drop in the cost of power flow control circuits. Schottky and $\mathrm{p}-\mathrm{i}-\mathrm{n}$ rectifiers are an attractive vehicle for demonstrating the high voltage performance of different materials systems and blocking voltages from $3-5.9 \mathrm{kV}$ have been reported in $\mathrm{SiC}$ devices. The reverse leakage current in Schottky rectifiers is generally far higher than expected from thermionic emission, most likely due to defect states around the contact periphery. To reduce this leakage current and prevent breakdown by surface flash-over, edge termination techniques such as guard rings, field plates, beveling or surface ion implantation are necessary. However in the few GaN rectifiers reported so far, there has been little effort on employing edge termination methods and no investigation of the effect of increasing the bandgap by use of AlGaN.

In this paper we will detail recent results in GaN power electronic devices, including Schottky rectifiers, HBTs, BJTs, MOSFETs and HEMTs. The pace of advancement of these technologies has been remarkably rapid in the past 2 years.

\section{GaN Rectifiers}

For these devices, the $\mathrm{GaN}$ was grown on c-plane $\mathrm{Al}_{2} \mathrm{O}_{3}$ substrates by Metal Organic Chemical Vapor Deposition using trimethylgallium and ammonia as the precursors. For vertically-depleting devices, the structure consisted of a $1 \mu \mathrm{m} \mathrm{n}{ }^{+}\left(3 \times 10^{18} \mathrm{~cm}^{-3}\right.$, Si-doped $)$ contact layer, followed by undoped $\left(\mathrm{n}=2.5 \times 10^{16}\right.$ $\mathrm{cm}^{-3}$ ) blocking layers which ranged from $3-11 \mu \mathrm{m}$ thick. These samples were formed into mesa diodes using Inductively Coupled Plasma etching with $\mathrm{Cl}_{2} / \mathrm{Ar}$ discharges $(300 \mathrm{~W}$ source power, $40 \mathrm{~W}$ rf chuck power). The dc self-bias during etching was $-85 \mathrm{~V}$. To remove residual dry etch damage, the samples were annealed under $\mathrm{N}_{2}$ at $800^{\circ} \mathrm{C}$ for 30 secs. Ohmic contacts were formed by lift-off of e-beam evaporated $\mathrm{Ti} / \mathrm{Al}$, annealed at $700^{\circ} \mathrm{C}$ for $30 \operatorname{secs}$ under $\mathrm{N}_{2}$ to minimize the contact resistance. Finally, the rectifying contacts were formed by lift-off of e-beam evaporated Pt/Au. Contact diameters of 60-1100 $\mu \mathrm{m}$ were examined.

For laterally-depleting devices, the structure consisted of $\sim 3 \mu \mathrm{m}$ of resistive (10 $0^{7} \mathrm{ohms}$ per square) $\mathrm{GaN}$. To form ohmic contacts, $\mathrm{Si}^{+}$was implanted at $5 \times 10^{14} \mathrm{~cm}^{-2}, 50 \mathrm{keV}$ into the contact region and activated by annealing at $150^{\circ} \mathrm{C}$ for 10 secs under $\mathrm{N}_{2}$. The resulting n-type carrier concentration was $1 \times 10^{19} \mathrm{~cm}^{-3}$. The ohmic and rectifying contact metallization was the same as described above.

Three different edge termination techniques were investigated for the planar diodes:

(i) use of a p-guard ring formed by $\mathrm{Mg}^{-}$implantation at the edge of the Schottky barrier metal. In these diodes the rectifying contact diameter was held constant at $124 \mu \mathrm{m}$, while the distance of the edge of this contact from the edge of the ohmic contact was $30 \mu \mathrm{m}$ in all cases.

(ii) use of p-floating field rings of width $5 \mu \mathrm{m}$ to extend the depletion boundary along the surface of the $\mathrm{SiO}_{2}$ dielectric, which reduces the electric field crowding at the edge of this

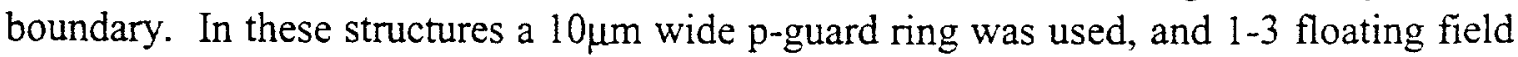
rings employed.

(iii) use of junction barrier controlled Schottky (JBS) rectifiers, i.e. a Schottky rectifier structure with a $p-n$ junction grid integrated into its drift region. 
In all of the edge-terminated devices the Schottky barrier metal was extended over an oxide layer at the edge to further minimize the field crowding, and the guard and field rings formed by $\mathrm{Mg}^{-}$implantation and $1100^{\circ} \mathrm{C}$ annealing.

Figure 1 (left) shows a schematic of the planar diodes fabricated with the p-guard rings, while the right of the Figure shows the influence of guard ring width on $\mathrm{V}_{B}$ at $25^{\circ} \mathrm{C}$. Without any edge termination, $V_{B}$ is $\sim 2300 \mathrm{~V}$ for these diodes. The forward turn-on voltage was in the range 15-50 V, with a best onresistance of $0.8 \Omega \mathrm{m}^{2}$. The figure-of-merit $\left(\mathrm{V}_{\mathrm{B}}\right)^{2} / \mathrm{R}_{\mathrm{ON}}$ was $6.8 \mathrm{MW} \cdot \mathrm{cm}^{-2}$. As the guard-ring width was increased, we observed a monotonic increase in $V_{B}$, reaching a value of $\sim 3100 \mathrm{~V}$ for $30 \mu \mathrm{m}$ wide rings. The figure-of-merit was $15.5 \mathrm{MW} \cdot \mathrm{cm}^{-2}$ under these conditions. The reverse leakage current of the diodes was still in the nA range at voltages up to $90 \%$ of the breakdown value. Similar results were obtained with the field rings or JBS control.

The results shown in Figure 1 are convincing evidence that proper design and implementation of edge termination methods can significantly increase reverse breakdown voltage in GaN diode rectifiers and will play an important role in applications at the very highest power levels. For example, the target goals for devices intended to be used for transmission and distribution of electric power or in single-pulse switching in the subsystem of hybrid-electric contact vehicles are $25 \mathrm{kV}$ standoff voltage, $2 \mathrm{kA}$ conducting current and forward voltage drop $<2 \%$ of the standoff voltage. At these power levels, it is expected that edge termination techniques will be essential for reproducible operation.

To place our results in context with reported $\mathrm{SiC}$ Schottky diode performance reported in literature, Figure 2 shows a plot of specific on-resistance versus reverse breakdown voltage for $\mathrm{SiC}$ and GaN diodes. together with the calculated (theoretical) performance. The $3.1 \mathrm{kV}$ result for GaN reported here is still well below the theoretical value, indicating that further improvement in processing and materials are needed. Some reported SiC devices have performance close to the theoretical limit, reflecting greater maturity of this technology at present.

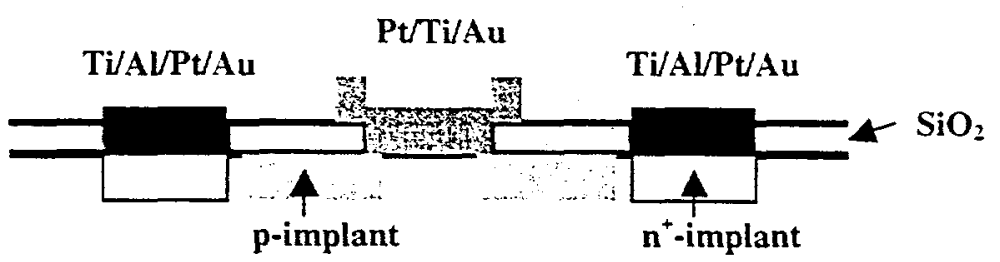

$3 \mu \mathrm{m}$ undoped GaN

$400 \AA$ GaN buffer layer

$\mathrm{Al}_{2} \mathrm{O}_{3}$ substrate

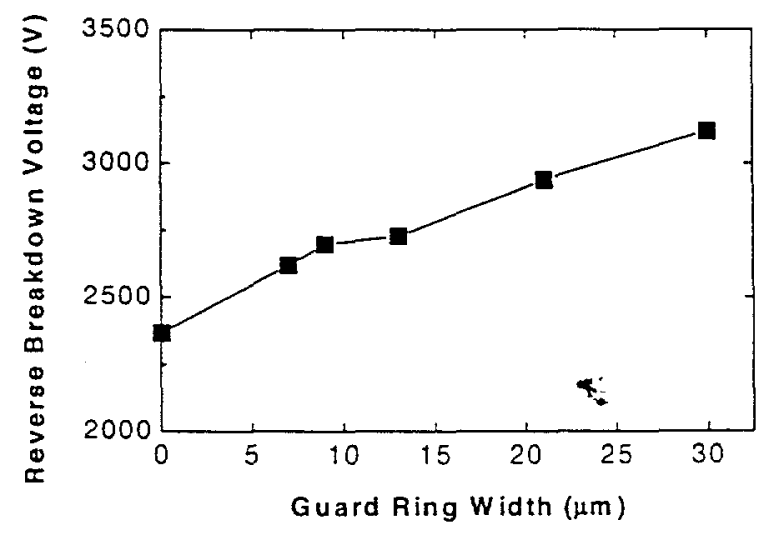

Guard Ring Width ( $\mu \mathrm{m}$ )

Figure 1. (left) View of rectifiers with p-type guard. (right) Variation of $V_{B}$ with guard ring width. 


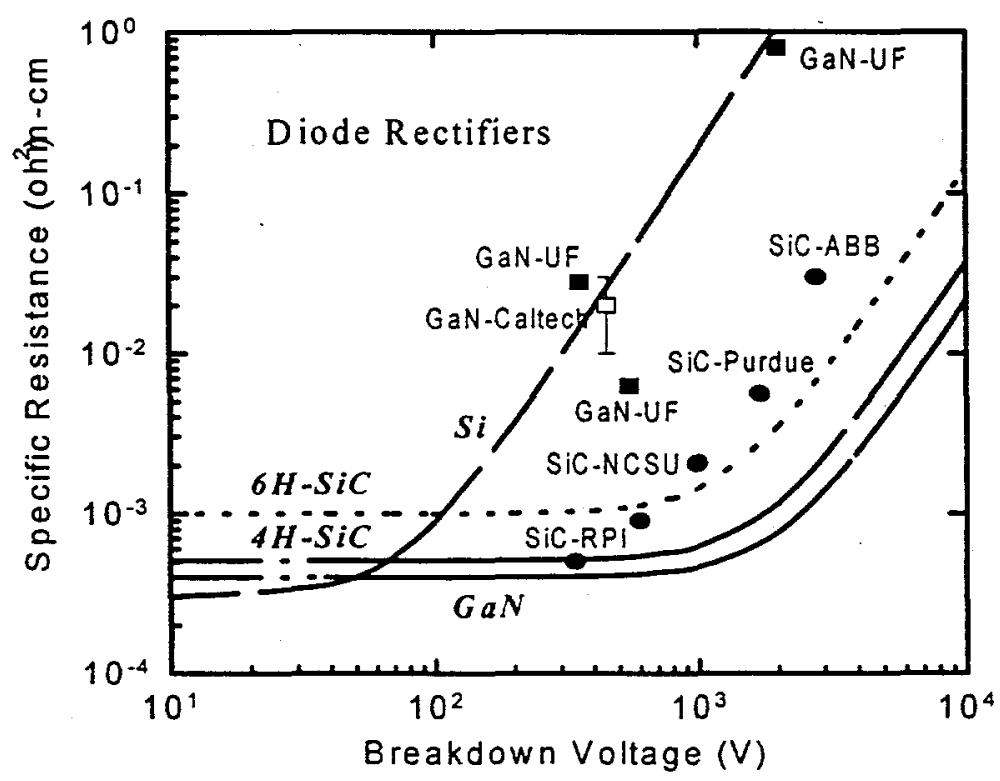

Figure 2. On-resistance versus blocking voltage for $\mathrm{SiC}$ and $\mathrm{GaN}$ diode rectifiers. The performance limits and GaN devices are shown by the solid lines.

\section{AlGaN Rectifiers}

The undoped $\mathrm{Al}_{\mathrm{x}} \mathrm{Ga}_{1-\mathrm{x}} \mathrm{N}$ layers were grown by atmospheric pressure Metal Organic Chemical Vapor Deposition at $1040^{\circ} \mathrm{C}$ (pure $\mathrm{GaN}$ ) or $1100^{\circ} \mathrm{C}$ (AlGaN) on (000l) oriented sapphire substrates. The precursors were trimethylgallium, trimethlygaluminum and ammonia, with $\mathrm{H}_{2}$ used as a carrier gas. The growth was performed on either GaN (in the case of GaN active layers) or AIN (in the case of AIGaN active layers) low temperature buffers with nominal thickness of $200 \AA$. The active layer thickness was $-2.5 \mu \mathrm{m}$ in all cases and the resistivity of these films was of order $10^{7} \Omega \mathrm{cm}$. To form ohmic contacts in some cases, $\mathrm{Si}^{+}$was implanted at $5 \times 10^{14} \mathrm{~cm}^{-2}, 50 \mathrm{keV}$ into the contact region and activated by annealing at $1150^{\circ} \mathrm{C}$ for $10 \mathrm{secs}$ under $\mathrm{N}_{2}$. The contacts were then formed by lift-off of e-beam. evaporated $\mathrm{Ti} / \mathrm{Al} / \mathrm{Pt} / \mathrm{Au}$ annealed at $700^{\circ} \mathrm{C}$ for 30 secs under $\mathrm{N}_{2}$. The rectifying contacts were formed by lift-off of ebeam evaporated $\mathrm{Pt} / \mathrm{Ti} / \mathrm{Au}$ (diameter $60-1100 \mu \mathrm{m}$ ). The on-resistance of the AlGaN diodes was higher than for pure GaN, due to higher ohmic contact resistance. The lowest $R_{\mathrm{ON}}$ achieved was $3.2 \Omega \mathrm{cm}^{2}$, leading to a figure-of-merit of $\sim 5.5 \mathrm{MW} \cdot \mathrm{cm}^{-2}$.

Figure 3 shows the variation of $\mathrm{V}_{\mathrm{RB}}$ with $\mathrm{Al}$ percentage in the $\mathrm{AlGaN}$ active layers of the rectifiers. In this case we are using the $V_{R B}$ values from diodes without any edge termination or surface passivation. The calculated bandgaps as a function of $\mathrm{Al}$ composition are also shown, and were obtained from the relation

$$
E g(x)=E g G a N(1-x)+E g A l N \cdot x-b x(1-x)
$$

where $x$ is the AlN mole fraction and $b$ is the bowing parameter with value $0.96 \mathrm{eV}$. Note that $\mathrm{V}_{\mathrm{RB}}$ does not increase in linear fashion with bandgap. In a simple theory $V_{R B}$ should increase as $(E g)^{1.5}$, but it has been empirically established that factors such as impact ionization coefficients and other transport parameters need to be considered and that consideration of Eg alone is not sufficient to explain measured $V_{R B}$ behavior. The fact the $V_{R B}$ increases less rapidly with $E g$ at higher $A I N$ mole fractions may indicate increasing concentrations of defects that influence the critical field for breakdown. 


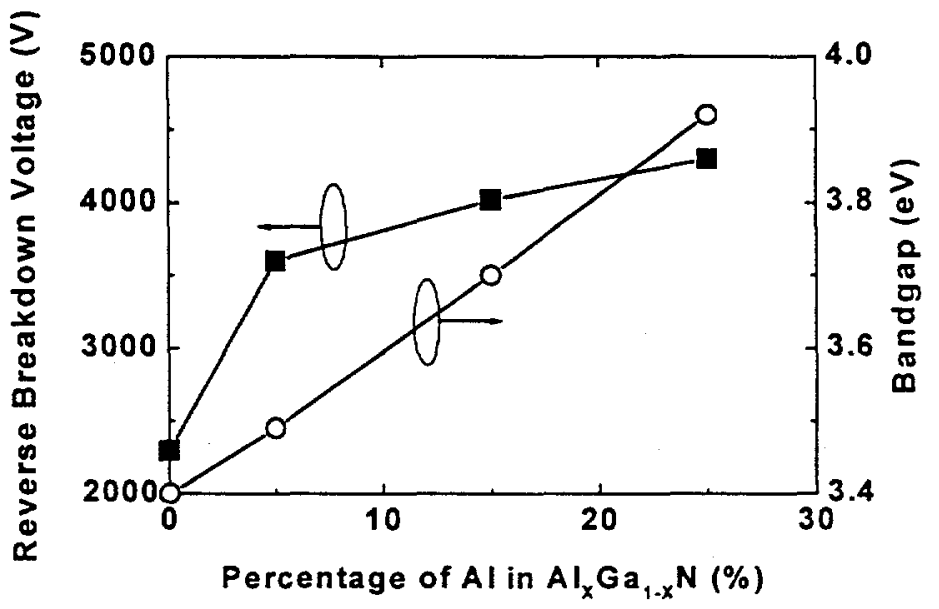

Figure 3. Variation of $\mathrm{V}_{\mathrm{RB}}$ in $\mathrm{Al}_{\mathrm{x}} \mathrm{Ga}_{1-\mathrm{x}} \mathrm{N}$ rectifiers without edge termination, as a junction of $\mathrm{Al}$ concentration. The bandgaps for the AlGaN alloys are also shown.

The reverse I-V characteristics of all of the rectifiers showed $I \propto V^{0.5}$ over a broad range of voltage ( 50 $2000 \mathrm{~V}$ ), indicating that Shockley-Read-Hall recombination is the dominant transport mechanism. The current density in all devices was in the range $5-10 \times 10^{-6} \mathrm{~A} \cdot \mathrm{cm}^{-2}$ at $2 \mathrm{kV}$. At low biases $(\leq 25 \mathrm{~V})$ the reverse current was proportional to the perimeter of the rectifying contact, suggesting that surface contributions are the most important in this voltage range. For higher biases, the current was proportional to the area of the rectifying contact. Under these conditions, the main contribution to the reverse current is from under this contact, i.e. from the bulk of the material. It is likely that the high defect density in heteroepitaxial GaN is a primary cause of this current.

When pushed beyond breakdown, the diodes invariably failed at the edges of the rectifying contact. As described earlier, the use of metal field plate contact geometries with $\mathrm{SiO}_{2}$ as the insulator and either guard rings or floating field rings significantly increased $\mathrm{V}_{\mathrm{B}}$. These rectifiers generally did not suffer irreversible damage to the contact upon reaching breakdown and could be re-measured many times.

\section{GaN/AIGaN Heterojunction Bipolar Transistors}

Both npn and pnp HBTs have been fabricated with emitter contact diameters in the range $50-100 \mu \mathrm{m}$. HBT power microwave amplifiers are mostly designed on common-emitter or common-base operation. The current gain is greater than unity only in the common-emitter mode, but the common-base mode is attractive because of the possibility of appreciable power gain obtained through the impedance transformation offered by this amplifier.

In all of our devices we have observed that the saturated collector current was nearly equal to themitter current, which indicates high emitter injection efficiency. Gummel plots showed dc current gains of 1520 at room temperature. In many of the devices it is difficult to obtain common-emitter operation due to leakage in the collector-base junction, and at all temperatures $\left(25-300^{\circ} \mathrm{C}\right)$ the junction ideality factors for both emitter-base and collector base junctions were close to 2 , indicative of significant recombination. By removing the base contact we observed no collector current, which confirms the transistor modulation.

For npn devices the performance is limited by the high base resistnace, which originates from the deep ionization level of the $\mathrm{Mg}$ acceptors. In these devices we have achieved maximum current densities of $2.55 \mathrm{kA} \cdot \mathrm{cm}^{-2}$ at $\mathrm{V}_{\mathrm{BC}}=8 \mathrm{~V}$, corresponding to power densities of $20.4 \mathrm{~kW} \cdot \mathrm{cm}^{-2}$. 


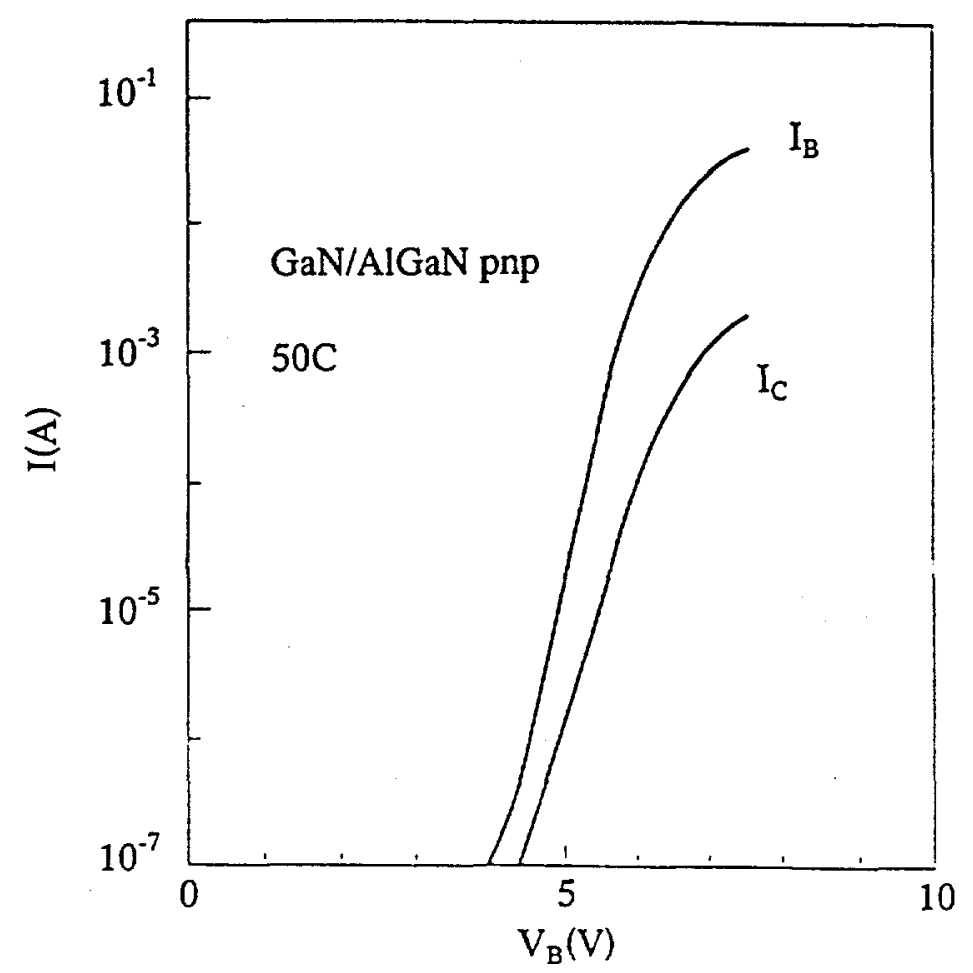

Figure 4. Gummel plot of pnp HBT with $\mathrm{V}_{\mathrm{CB}}=0$.

There are two advantages to the pnp configuration for AlGaN/GaN HBTs. Firstly, there is a large emitter-base energy bandgap offset than in npn structures, and secondly, the base resistance will be much lower due to higher doping level achievable in n-type material. The best pnp HBTs we fabricated can be operated up to current densities of over $2 \mathrm{kA} \cdot \mathrm{cm}^{-2}$ at $25 \mathrm{~V}$, corresponding to power densities above $50 \mathrm{~kW} \cdot \mathrm{cm}^{-2}$. A Gummel plot is shown in Figure 4.

\section{GaN Bipolar Junction Transistors}

The epitaxial growth of BJTs is simpler than for HBTs because the emitter layer is comprised of GaN rather than AIGaN. In our npn devices we have achieved maximum current densities of $3.6 \mathrm{kA} \cdot \mathrm{cm}^{-2}$ at a collector-base voltage of $15 \mathrm{~V}$, corresponding to a power density of $54 \mathrm{~kW} \cdot \mathrm{cm}^{-2}$. The maximum commonemitter dc current gain was -15 for temperatures up to $300^{\circ} \mathrm{C}$. The operation of both GaN BJTs and GaN/AIGaN HBTs was simulated using a program based on the drift-diffusion model. This simulation showed that at low current densities the HBT enjoys and advantage due to the conduction band offset, but that at higher current densities the results converged. This suggests that simple BJTs are useful as power devices.

The dc characteristics were measured up to a $V_{B C}$ of $65 \mathrm{~V}$ in the common-base mode. A stable current density of $204 \mathrm{~A} \cdot \mathrm{cm}^{-2}$ was run at this voltage, corresponding to a power density of $40 \mathrm{~kW} \cdot \mathrm{cm}^{-2}$. These values can clearly be increased by optimized design of the layer structure and mask layout. The devices showed little fall-off in performance at temperatures up to $250^{\circ} \mathrm{C}$. 


\section{GaN Metal Oxide Semiconductor Field Effect Transistors}

A GaN depletion-mode metal oxide semiconductor field effect transistor was demonstrated, using $\mathrm{Ga}_{2} \mathrm{O}_{3}\left(\mathrm{Gd}_{2} \mathrm{O}_{3}\right)$ as the gate dielectric, similar to the approach reported for GaAs and InGaAs. The MOS gate reverse breakdown voltage was $>35 \mathrm{~V}$, significantly higher than obtained using a simple Pt Schottky gate on the same material. A maximum extrinsic transconductance of $15 \mathrm{mS} \cdot \mathrm{mm}^{-1}$ was obtained at $V_{D S}=$ $30 \mathrm{~V}$ and device performance was limited by the contact resistance. A unity current gain cut-off frequency, $f_{\mathrm{T}}$, and maximum frequency of oscillation, $\mathrm{f}_{\mathrm{MAX}}$, of 3.1 and $10.3 \mathrm{GHz}$, respectively were measured at $V_{D S}=25 \mathrm{~V}$ and $V_{G S}=-20 \mathrm{~V}$. The device performance can be improved by optimizing the layer structure using a thin and heavily doped channel layer, which will reduce the contact resistance and enhance the transconductance.

\section{Summary}

Tremendous progress has been made in advancing the growth, processing and design of GaN power electronics in recent times. There are as yet no commercially-available devices and this may take another 3-5 years to occur.

\section{Acknowledgments}

The work at the various institutions has been supported by ONR (J.C. Zolper), DARPA (D. Radack), EPRI (B. Damsky), NSF (L. Hess), by BMDO, and National Science Council of ROC. Sandia is a multiprogram laboratory operated by Sandia Corporation, a Lockheed-Martin company, for the US Department of Energy.

\section{References}

$$
\begin{aligned}
& \text { Sundia is a multiproeram laboratory } \\
& \text { nerated by Sundia Corporation, a } \\
& \text { Luenhed Varen (imnany, for the } \\
& \text { Enicd Suth Derument of Energy }
\end{aligned}
$$

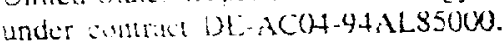

[1] see for example, M.S. Shur and M.A. Khan, in GaN and Related Materials II, ed. S.J. Pearton (Gordon and Breach, NY, 2000).

[2] S.C. Binari, L.B. Rowland, W. Kruppa, G. Kelner, K. Doverspike and D.K. Gaskill, Electron. Lett. 30, 1248 (1994).

[3] L.F. Eastman, K.G. Chu, J. Smart and J.R. Shealy, Mat. Res. Soc. Symp. Proc. 512, 3 (1998).

[4] S.T. Sheppard, K. Doverspike, W.L. Pribble, S.T. Allen and J.W. Palmour, $56^{\text {th }}$ Device Research Conference, Charlottesville, VA, June 1998).

[5] Y.-F. Wu, B.J. Thibeault, B.P. Keller, S. Keller, S.P. DenBaars and U.K. Mishra, Topical Workshop on Heterostructure Electronics, Kanagawa, Japan, September 1998.

[6] L. Daumiller, L. Kirchner, M. Kamp, K.J. Eheling, L. Pond, C.E. Weitzel and E. Kohn, $56^{\text {th }}$ Device Research Conference, Charlottesville, CA, June 1998 